\title{
Poland syndrome: neonatal presentation with axillary pterygium
}

\author{
Tânia dos Santos Mendo, Teresa Almeida, Ana Teresa Maria, Madalena Lopo Tuna
}

Neonatology, Hospital de São Francisco Xavier, Centro Hospitalar de Lisboa Ocidental, Lisboa, Portugal

\section{Correspondence to}

Dr Tânia dos Santos Mendo; mendotania.tfdsm@gmail.com

Accepted 2 March 2021

\section{DESCRIPTION}

Poland syndrome is a congenital syndrome, described for the first time in 1841 by Sir Alfred Poland. ${ }^{12}$ The estimated incidence is $1 / 30000$ to $1 / 32000$ live births, ${ }^{2}$ predominantely affecting men, varying from $2: 1$ to $3: 1 .^{1}$ The defect is more frequently unilateral and on the right side (75\%). ${ }^{1}$ The majority of cases are sporadic. ${ }^{12}$ However, there have been reports of familial cases. ${ }^{12}$

We describe a female infant born at 38 weeks, second child of a 37-year-old mother with chronic high blood pressure and no relevant family history. Antenatal ultrasounds were described as normal. Maternal serologies (Venereal Disease Research Laboratory (VDRL), hepatitis C virus (HCV), hepatitis B virus (HBV), HIV and toxoplasmosis) were negative with immunity to rubella. Third trimester urine culture and streptococcus group b (GBS) were negative.

Uncomplicated, eutocic delivery with Apgar score $9 / 10 / 10$. Birth weight was $3185 \mathrm{~g}\left(\mathrm{P}_{50}\right)$, length $47,5 \mathrm{~cm}\left(\mathrm{P}_{15-50}\right)$, head circumference $34 \mathrm{~cm}\left(\mathrm{P}_{50}\right)$.

Physical examination at 15 hours of life showed right thoracic asymmetry and axillary pterygium related to pectoralis muscle agenesis (figure 1), posteriorly confirmed by ultrasound. There were

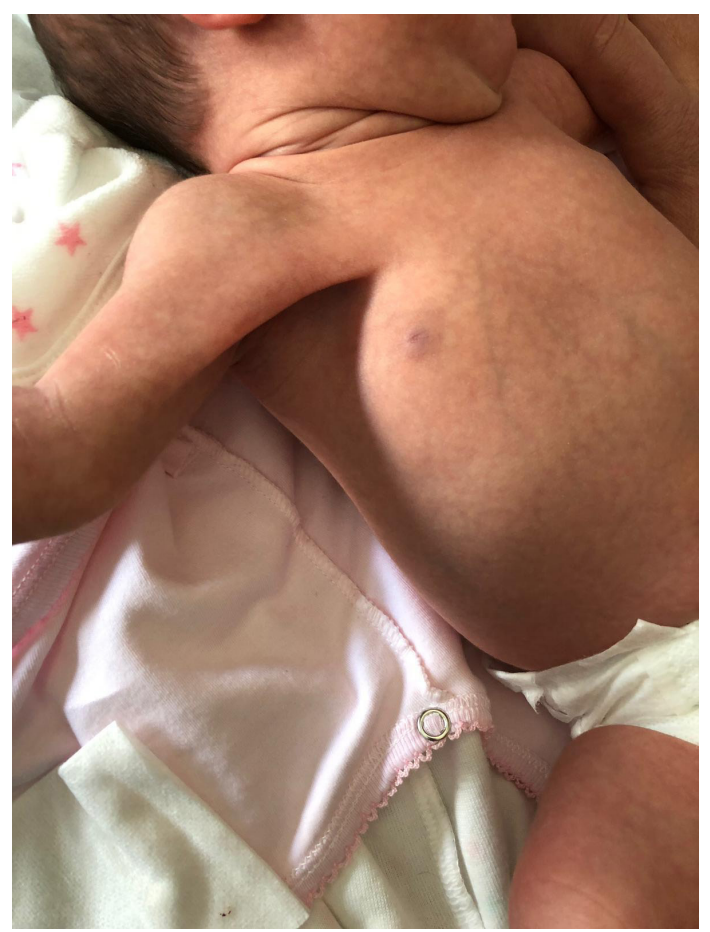

Figure 1 Axillary pterygium related to pectoralis muscle agenesis.

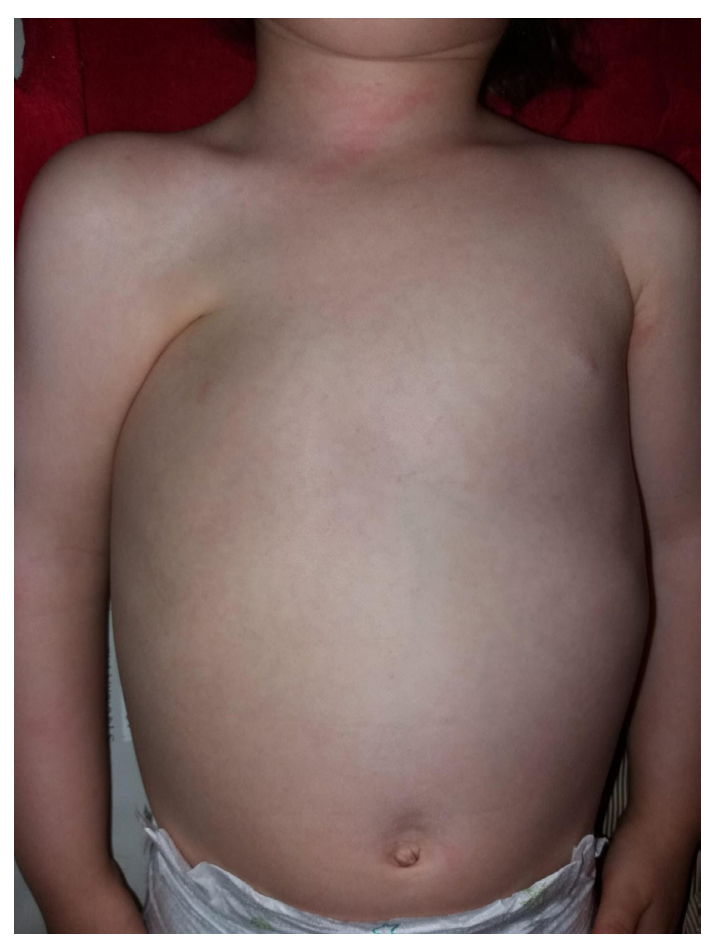

Figure 2 Right thoracic asymmetry.

Learning points

Patients with Poland syndrome present with a spectrum of defects that includes a wide phenotypical variability.

- These patients should be followed up strictly, with special attention to pulmonary and muscle functions, as well as breast development. Subsequent surgical interventions may be necessary, including breast reconstruction in puberty.

- Early and accurate diagnosis allows adequate treatment and follow-up, as well as timely surgical correction.

no other associated clinical defects, namely rib cage or upper limb abnormalities. Chest X-ray and additional studies including echocardiogram, brain, abdominal and renal ultrasounds were normal.

She was discharged at 48 hours of life, maintaining a regular follow-up by a multidisciplinary team (physiatry, plastic surgery and pneumology). Currently at 22 months old, thoracic asymmetry with reduced right-sided subcutaneous fat and axillary pterygium are evident (figure 2). Ultrasound scan confirmed a residual sternoclavicular portion 
of the pectoralis major muscle, conditioning the tendinous axillary band. Surgical release will be considered when functional limitations occur. Future reconstructive breast surgery may also be an asset.

Poland syndrome is typically characterised by absence or hypoplasia of the pectoralis major muscle (mandatory feature), absence or hypoplasia of the pectoralis minor muscle, abnormalities of the chest wall, hypoplasia or absence of the nipple and ipsilateral upper extremity abnormalities. ${ }^{1-3}$ Phenotypical presentation is wide and multiple combinations of these clinical defects are possible. In this case, the defect is isolated pectoralis muscle agenesis, representing the minimal form or type 1 , according to recent classification of Poland syndrome. ${ }^{2}$

The pathogenesis is unknown, the most accepted hypothesis points to a dysembryological process caused by a vascular defect of the subclavian artery around the sixth week of pregnancy leading to an early insufficient blood flow to the chest and limb. ${ }^{1-3}$

In most cases, functional disability is mild, treatment relies mainly in surgery and the main goal is to improve the symmetry of the chest wall and to correct breast hypoplasia. ${ }^{1-3}$
Twitter Teresa Almeida @Dr

Contributors TFdSM: data acquisition, bibliography review, manuscript writing and discussion. TA: bibliography review, manuscript writing and discussion. ATM: conception and design, bibliography review, acquisition of photos, discussion, planning and review of manuscript. MLT: conception and design, discussion and final review of manuscript.

Funding The authors have not declared a specific grant for this research from any funding agency in the public, commercial or not-for-profit sectors.

Competing interests None declared.

Patient consent for publication Parental/guardian consent obtained.

Provenance and peer review Not commissioned; externally peer reviewed.

\section{REFERENCES}

1 Vazirnia A, Cohen PR. Poland's syndrome: a Concise review of the clinical features highlighting associated dermatologic manifestations. Am J Clin Dermatol 2015;16:295-301.

2 Romanini MV, Calevo MG, Puliti A, et al. Poland syndrome: a proposed classification system and perspectives on diagnosis and treatment. Semin Pediatr Surg 2018;27:189-99.

3 Baldelli I, Baccarani A, Barone C, et al. Consensus based recommendations for diagnosis and medical management of Poland syndrome (sequence). Orphanet J Rare Dis 2020;15:201.

Copyright 2021 BMJ Publishing Group. All rights reserved. For permission to reuse any of this content visit

https://www.bmj.com/company/products-services/rights-and-licensing/permissions/

BMJ Case Report Fellows may re-use this article for personal use and teaching without any further permission.

Become a Fellow of BMJ Case Reports today and you can:

- Submit as many cases as you like

- Enjoy fast sympathetic peer review and rapid publication of accepted articles

- Access all the published articles

- Re-use any of the published material for personal use and teaching without further permission

\section{Customer Service}

If you have any further queries about your subscription, please contact our customer services team on +44 (0) 2071111105 or via email at support@bmj.com.

Visit casereports.bmj.com for more articles like this and to become a Fellow 